\title{
FACTORS ASSOCIATED WITH ANTI-DEPRESSANT MEDICATION ADHERENCE IN WOMEN ATTENDING AN OUT PATIENT PSYCHIATRY DEPARTMENT
}

\author{
Dr. Mrinalini Reddy ${ }^{(1)}$, Dr. Pallavi Abhilasha ${ }^{(1)}$, Dr. M. Thirunavukarasu ${ }^{(1)}$, Dr. R. Raj- \\ kumar $^{(1)}$, Dr. M. Suresh Kumar ${ }^{(1)}$ \\ ${ }^{1-}$ Department of Psychiatry, SRM Medical College Hospital and Research Centre
}

\begin{abstract}
Introduction: Treatment adherence and illness may not be related only by the severity of the illness but by so many other factors which impact on seeking and continuing treatment; yet severity of the illness will be one of the major factors influencing treatment adherence.

Methods: Female patients attending the psychiatric OPD, diagnosed with depression as per ICD10 guidelines and provided informed consent participated in this questionnaire-based study. A total of 135 patients who attended the OPD in 9 months were assessed for the severity of depression and medication adherence by administering scales to assess the severity of depression and medication adherence was assessed by questioning about the drug taking and hospital attending behaviour. Out of this, thirty-one were attending for the first episode and hence were excluded from the analysis.

Results: Out of the 104 female patients diagnosed with depression of more than one episode, 44 $(42.3 \%)$ had mild depression, $52(50 \%)$ had moderate depression and $8(7.7 \%)$ had severe depression. Twenty-nine women $(27.9 \%)$ were on medications and $75(72.1 \%)$ women were not taking their medications. While greater proportion of women with mild depression were adherent to medication (51.7\%), more women with moderate depression didn't adhere to medication $(54.7 \%)$, even though such difference was statistically not significant. Older age, having a paid work and married status were significantly associated with medication (antidepressants) adherence.

Conclusions: Our results indicate that medication adherence is associated with factors other than severity of depression. Work and marital status played a significant role in determining the adherence to antidepressant medications among women.

Keywords: Depression, medication adherence, compliance, female patients
\end{abstract}

\section{Corresponding author :}

Dr Mrinalini Reddy

SRM Medical College \& Research Center

onedirection161092@gmail.com 


\section{INTRODUCTION}

Depressive disorders are managed by medications and psychotherapy; both are combined at times for a more comprehensive approach. Mainstay of the treatment is by medication which are antidepressants. Continued medications have beneficial effect, but only if the treatment regime is adhered to.

Treatment adherence is influenced by many factors and one of them is the perceived distress arising out of the disease. The reasons behind nonadherence are varied and can be due to patient factors or due to clinician factors or both.

Distress cannot be measured objectively but the severity of the illness can be measured. The other factors are in the domain of psychological and social spheres. Continued adherence to the treatment regime helps in maintaining improvement. Factors which impact on treatment adherence have been studied by various workers in India and abroad. This study is an effort to assess the relationship between severity of the illness and treatment adherence.

The STAR*D Trial was a landmark study done for the management of depression. ${ }^{(1)}$ The current Practice Guideline for the Treatment of Patients with Major Depressive Disorder ${ }^{(2)}$ describes phasic pharmacological treatment of depression with the acute phase lasting 4 to 8 weeks, the continuation phase lasting 4 to 9 months. A study done by Trivedi et al concludes that only 25 to 50 percent of patients with major depression adhere to treatment ${ }^{(3)}$. Another similar study done by Keller et al showed that patient adherence with antidepressant medication is poor ${ }^{(4)}$.

Depressive symptoms can cause clinically significant impairment or distress in occupational, social or other important areas in functioning. Though the illness may be severe other factors like the lack of motivation, the depressogenic schemata, and a host of other factors may influence medication adherence. The mere presence of this disorder can significantly hamper a person to carry on with their daily activities and a lack of understanding of this disorder can contribute to non-adherence or even refusal to take medications.

Patient adherence to medications, in this case anti-depressant therapy is a critical aspect of effective clinical management. According to contemporary data attained over the past few years, about 50 percent of psychiatric patients and 50 percent of primary care patients prematurely discontinue antidepressant therapy (i.e., are non-adherent when assessed at 6 months after the initiation of treatment). ${ }^{(5)}$ Treatment adherence and illness is not related only by the severity of the illness but by so many other factors which impact on seeking and continuing treatment.
The objectives of our study are to assess the relationship between the severity of depression [assessed by Hamilton Depression Rating scale (HAMD)] and treatment adherence (specific questions addressed to the patient and the caregiver) and to study other factors associated with treatment nonadherence.

\section{METHODS}

\section{Method of Collection of Data}

This study has been performed in a tertiary care centre in South India. As per the Global Burden of Disease, 2000, the lifetime prevalence for Major Depressive Disorder is $10-25 \%$ for women. After approval from the institution's ethical committee, we proceeded by selecting 135 female patients who were diagnosed with Depression. They attended the Psychiatry Out Patient Department between May 2017 to January 2018. Thirty-one patients were excluded from this analysis as they had attended the department for the first episode of depressive disorder.

\section{Participants}

We included those female patients attending the psychiatric OPD at SRM Medical College, Hospital and Research Centre, who are diagnosed with Depression (Mild, Moderate or Severe) as per ICD-10 guidelines and provided written informed consent. Those excluded include patients with co-morbid psychiatric illnesses and patients unwilling to take part in our study.

\section{Questionnaires}

The questionnaires included general information of each participant. Mini International Neuropsychiatric interview (M.I.N.I) was given to rule out psychopathology other than depression. The severity of depression was assessed by using the Hamilton Depression Rating Scale (HAM-D). Medication adherence was assessed by questioning about the drug taking and hospital attending behaviour. No formal questionnaire was used. Participants were asked to review and follow-up weekly and their informants were also questioned regarding their adherence to medications.

\section{Statistical Analysis:}

Statistical analysis was done by SPSS (version 22) software. Chi square test and t-test were used to analyse the data. 


\section{RESULTS}

Figure 1: Medication use among study population $(\mathrm{N}=104)$

Proportion of women taking and not taking antidepressants

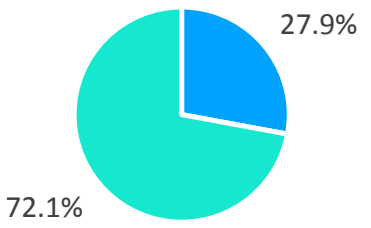

- Taking antidepressants

Of the 104 subjects participated in the study, 75 $(72.1 \%)$ were not taking antidepressants regularly indicating medication adherence in depressive disorders is low (Fig 1). Regularly in this sense means taking their medications daily.

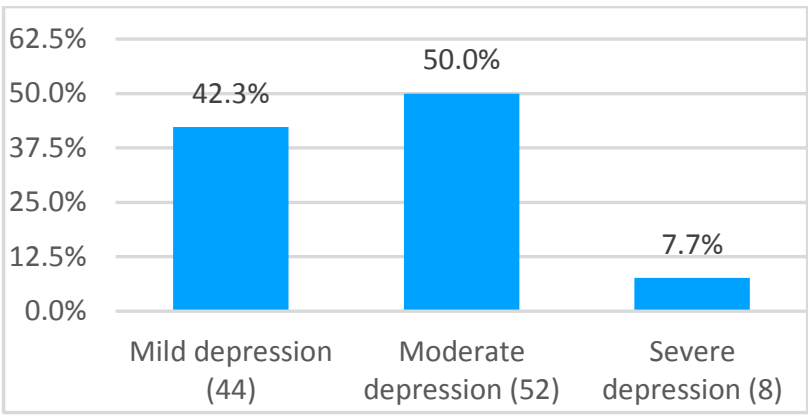

Of the 104 women, $44(42.3 \%)$ have mild depression, $52(50 \%)$ have moderate depression and $8(7.7 \%)$ have severe depression. (Fig. 2)

Table 1: Comparison of demographic and other clinical characteristics between study groups based on medication use $(\mathrm{N}=104)$

Figure 2: Severity of depression of study groups $(\mathrm{N}=104)$

\begin{tabular}{|c|c|c|c|c|c|c|c|}
\hline \multirow[t]{2}{*}{ Characteristic } & \multicolumn{2}{|c|}{$\begin{array}{l}\text { Medication group } \\
(\mathrm{N}=29)\end{array}$} & \multicolumn{2}{|c|}{$\begin{array}{l}\text { Not on medication group } \\
(\mathrm{N}=75)\end{array}$} & \multirow[t]{2}{*}{ Chi square } & \multirow[t]{2}{*}{$\begin{array}{l}\text { Mean differ- } \\
\text { ence }(95 \% \mathrm{CI})\end{array}$} & \multirow[t]{2}{*}{ P Value } \\
\hline & $\mathrm{n}(\%)$ & $\begin{array}{l}\text { Mean } \pm \\
\text { SD }\end{array}$ & $\mathrm{n}(\%)$ & $\begin{array}{l}\text { Mean } \pm \\
\text { SD }\end{array}$ & & & \\
\hline Age & & $\begin{array}{l}39.28 \pm \\
3.29\end{array}$ & & $\begin{array}{l}30.27 \pm \\
4.34\end{array}$ & & $\begin{array}{l}9.01(7.24, \\
10.78)\end{array}$ & $<0.001$ \\
\hline $\begin{array}{l}\text { Education } \\
\text { Primary } \\
\text { Secondary } \\
\text { Graduate } \\
\text { Post graduate }\end{array}$ & $\begin{array}{l}3(10.3 \%) \\
3(10.3 \%) \\
21(72.4 \%) \\
2(6.9 \%)\end{array}$ & & $\begin{array}{l}4(5.3 \%) \\
22(29.3 \%) \\
46(61.3 \%) \\
3(4.0 \%)\end{array}$ & & 4.681 & & 0.197 \\
\hline $\begin{array}{l}\text { Marital status } \\
\text { Single } \\
\text { Married } \\
\text { Divorced } \\
\text { Widow }\end{array}$ & $\begin{array}{l}0(0.00 \%) \\
25(86.2 \%) \\
3(10.3 \%) \\
1(3.4 \%)\end{array}$ & & $\begin{array}{l}17(22.7 \%) \\
57(76.0 \%) \\
1(1.3 \%) \\
0(0.00 \%)\end{array}$ & & 13.852 & & 0.003 \\
\hline $\begin{array}{l}\text { Work status } \\
\text { Paid work } \\
\text { Others }\end{array}$ & $\begin{array}{l}15(51.7 \%) \\
14(48.3 \%)\end{array}$ & & $\begin{array}{l}21(28 \%) \\
54(72 \%)\end{array}$ & & 5.201 & & 0.023 \\
\hline $\begin{array}{l}\text { Severity of depres- } \\
\text { sion } \\
\text { Mild depression } \\
\text { Moderate depres- } \\
\text { sion } \\
\text { Severe depression }\end{array}$ & $\begin{array}{l}15(51.7 \%) \\
11(37.9 \%) \\
3(10.3 \%)\end{array}$ & & $\begin{array}{l}29(38.7 \%) \\
41(54.7 \%) \\
5(6.7 \%)\end{array}$ & & 2.382 & & 0.304 \\
\hline HAM-D total score & & $\begin{array}{l}12.59 \pm \\
3.93\end{array}$ & & $\begin{array}{l}13.21 \pm \\
3.39\end{array}$ & & $\begin{array}{l}-0.63(-2.17 \\
0.91)\end{array}$ & 0.421 \\
\hline
\end{tabular}


The mean age of subjects on medication was $39.28 \pm 3.29$ and mean age of subjects not on medication was $30.27 \pm 4.34$. The mean difference 9.01 (95\% CI 7.24 to 10.78 ) between two groups was statistically significant $(\mathrm{P}$ value $<0.001) . \mathrm{n}$.

There was no difference between these groups on any of the parameters, especially the severity of depression.

Table 2: Stated reasons for non-adherence to antidepressants $(\mathbf{N}=\mathbf{7 5})$

\begin{tabular}{|l|c|}
\hline $\begin{array}{c}\text { Reasons cited for non-adherence to } \\
\text { medications }\end{array}$ & $\begin{array}{c}\text { Proportion } \\
\text { n (\%) }\end{array}$ \\
\hline $\begin{array}{l}\text { Low education about nature of de- } \\
\text { pression and course of illness }\end{array}$ & $64(85.3 \%)$ \\
\hline Side effects of antidepressants & $60(80 \%)$ \\
\hline Poor family support & $68(90.7 \%)$ \\
\hline
\end{tabular}

Among the 75 patients who were on not taking medications regularly, $85.3 \%$ people had a low education about the nature and course of the illness, $80 \%$ people experienced some kind of side effects due to the antidepressant they were taking and $90.7 \%$ people had a poor family support.

\section{DISCUSSION}

Among the 104 patients included in the study, $27.9 \%$ adhered to their medication regularly as advised, while $72.1 \%$ did not adhere to their medication regularly. Among the study participants, $42.3 \%$ were assessed to have mild depression, $50 \%$ have moderate depression, and $7.7 \%$ have a severe form of depression. Adherence was measured by direct questioning and no structured questionnaire was used. Banerjee and Verma have stated that non adherence is three times more common in women. ${ }^{(6)}$ Our study concentrated on women patients only. This is in contrast to the study by Sri Chaitanya et al who have noted the incidence of non adherence in the age group of 41-50 whereas the incidence was more common in younger age group. ${ }^{(7)}$ This study has also identified patient related factors of poor education, single status and younger age as contributing to non adherence. Tamburrino et al have noted that women below 40 years were represented more in non adherence group. ${ }^{(8)}$ Lucca et al in their study of non adherence in psychiatric patients also have noted that low level of education is one of the factors associated with non adherence. ${ }^{(9)}$ In our study, the mean HAM-D score is not statistically significantly different from the drug adherent group. If the group is divided on the basis of scores in the HAM-D scale, it shows that the moderate depressives are represented more in the nonadherent group. As most of the patients in our sample was either mild or moderate in severity it is possible that we were unable to find a difference in outcome related to severity of the symptoms. Non-adherence in this group appears to be more related to social and individual factors rather than disease related factors. In contrast with our outcomes Rieckmann et al have noted that severity of depression was associated with medication non adherence in their study. ${ }^{(10)}$

Other studies have found several factors that could contribute to non-adherence.Bulloch and Patten (11) found that simply forgetting was the main reason for patient non-adherence. Fortney et al ${ }^{(12)}$ concluded that the side effects of antidepressants were a commonly cited reason for it's discontinuation. Kennedy et al ${ }^{(13)}$ found that a lower adherence to antidepressants was associated with an increased cost of the medication, out of pocket costs, patients perception of the need and side effects of medication. Deterrents to adherence may also include : medication-induced sexual dysfunction; ${ }^{(14)}$ concerns that antidepressants might change their personality; ${ }^{(15)}$ patient beliefs against antidepressants ${ }^{(16)}$ delayed onset of effect; ${ }^{(17)}$ poor psychoeducation ${ }^{(18)}$ specific personality characteristics of patients such as extraversion ${ }^{(19)}$ and/or Cluster $\mathrm{B}^{(20)}$ or other personality disorder symptoms; ${ }^{(21)}$ patient substance abuse; ${ }^{(215)}$ patient fears of addiction; ${ }^{(22)}$ lower patient depression severity; ${ }^{(23)}$ complicated titration or dosing schedule of the medication; ${ }^{(24)}$ lack of follow-up care by the clinician; ${ }^{(24)}$ and low patient motivation. ${ }^{(24)}$

\section{LIMITATIONS}

In this study, non adherence was simply assessed by drug taking and hospital seeking behaviour. Reason for non adherence was not assessed. A more comprehensive study including disease related and medication related factors would have added more value to the study.

\section{CONCLUSION}

In this study, severity of depression was not associated with medication non adherence, married status and paid work status are factors associated with adherence to antidepressants. Stated reasons for nonadherence of medications include less education about the nature and outcome of depression, side effect profile and poor family support. Psychoeducation of patients \& caregivers,carefully monitoring of medication adherence an ongoing followup are crucial to enhance adherence.

\section{CONFLICTS OF INTEREST}

The authors declare no conflict of interest. 


\section{REFERENCES}

1. Gaynes BN, Warden D, Trivedi MH, et al. What did STAR*D teach us? Results from a large-scale, practical, clinical trial for patients with depression. Psychiatry Serv. 2009;60:1439-1445.

2. American Psychiatric Association. Practice Guideline for the Treatment of Patients with Major Depressive Disorder, 3rd Edition. Washington, DC: American Psychiatric Press Inc; 2010.

3. Trivedi MH, Lin EH, Katon WJ. Consensus recommendations for improving adherence, selfmanagement, and outcomes in patients with depression. CNS Spectr. 2007;12:S1-27.

4. Keller MB, Hirschfeld RM, Demyttenaere K, Baldwin DS. Optimizing outcomes in depression: focus on antidepressant compliance. Int Clinical Psychopharmacology.2002;17:265-271.

5. Innov Clin Neurosci. 2012 May; 9(5-6):416.Antidepressant adherence: are patients taking their medications? Sansone RA, Sansone LA. Departments of Psychiatry and Internal Medicine, Wright State University School of Medicine in Dayton, Ohio, USA.

6. Hindawi Publishing Corporation Depression Research and Treatment, Factors Affecting NonAdherence among Patients Diagnosed with Unipolar Depression in a Psychiatric Department of a Tertiary Hospital in Kolkata, India by Sohini Banerjee and Ravi Prasad Varma. Volume 2013, Article ID 809542.

7. The International Journal of Indian Psychology Reasons for Poor Medication Adherence in Patients with Depression by D. Sri Chaitanya et al, ISSN 2348-5396 (e) | ISSN: 2349-3429 (P) Volume 3, Issue 2, No.6.

8. Primary Care Companion to the Journal of Clinical Psychiatry Antidepressant Medication Adherence: A Study of Primary Care Patients by Marijo B. Tamburrino et al 2009; 11(5): 205-211.

9. Incidence and factors associated with medication non adherence in patients with mental illness a cross sectional study, Lucca JM, Ramesh M, Parthasarathy G \&Ram D, Journal of Post graduate medicine 2015, vol :61, pp251-56

10. SSRI Use, Depression and Long-Term Outcomes after an Acute Coronary Syndrome - A Prospective Cohort Study, Nina Rieckmann et al, JAMA Intern Med. 2013 Jun 24; 173(12): 1150-1151.

11. Bulloch AG, Patten SB. Nonadherence with psychotropic medications in the general population. Soc Psychiatry Epidemiology. 2010;45:47-56.

12. Fortney JC, Pyne JM, Edlund MJ, et al. Reasons for antidepressant nonadherence among Veterans treated in primary care clinics. J Clinical Psychiatry. 2011;72:827-834.
13. Kennedy J, Tuleu I, Mackay K. Unfilled prescriptions of Medicare beneficiaries: prevalence, reasons, and types of medicines prescribed. J Manag Care Pharm. 2008;14:553-560.

14. Cohen S, Khn KU, Strter B, et al. Adverse sideeffect on sexual function caused by psychotropic drugs and psychotropic substances. Nervenarzt. 2010;81:1129-1139.

15. Chakraborty K, Avasthi A, Kumar S, Grover S. Attitudes and beliefs of patients of first episode depression towards antidepressants and their adherence to treatment. Soc Psychiatry Psychiatric Epidemiology. 2009;44:482-488.

16. Hoencamp E, Stevens A, Haffmans J. Patients' attitudes toward antidepressants. Psychiatr Serv. 2002;53:1180-1181.

17. Keller MB, Hirschfeld RMA, Demyttenaere K, Baldwin DS. Optimizing outcomes in depression: focus on antidepressant compliance. Int Clinical Psychopharmacology. 2002;17:265-271.

18. Woolley SB, Fredman L, Goethe JW, et al. Hospital patients' perceptions during treatment and early discontinuation of serotonin selective reuptake inhibitor antidepressants. J Clinical Psychopharmacology. 2010;30:716-719.

19. Cohen NL, Ross EC, Bagby RM, et al. The 5factor model of personality and antidepressant medication compliance. Can J Psychiatry. 2004;49:106113.

20. Holma IA, Holma KM, Melartin TK, Isometsa ET. Treatment attitudes and adherence of psychiatric patients with major depressive disorder: a five-year prospective study. J Affect Disord. 2010;127:102112.

21. Akerblad AC, Bengtsson F, Holgersson M, et al. Identification of primary care patients at risk of nonadherence to antidepressant treatment. Patient Prefer Adherence. 2008;2:379-386.

22. Brown C, Battista DR, Bruehlman R, et al. Beliefs about antidepressant medications in primary care patients: relationship to self-reported adherence. Med Care. 2005;43:1203-1207.

23. Demyttenaere K, Adelin A, Patrick M, et al. Sixmonth compliance with antidepressant medication in the treatment of major depressive disorder. Int Clin Psychopharmacol. 2008;23:36-42.

24. Massand PS., Tolerability and adherence issues in antidepressant therapy. Clin Ther. 2003; 25: 22892304. 